\title{
Passado e futuro dos jornais mais longevos do Brasil
}

\author{
DOI: https://doi.org/10.1590/1809-58442021115
}

\author{
Otávio Daros ${ }^{1}$ \\ https://orcid.org/0000-0003-0738-8207
}

${ }_{1}^{1}$ (Pontifícia Universidade Católica do Rio Grande do Sul, Escola de Comunicação, Artes e Design, Programa de Pós-Graduação em Comunicação Social. Porto Alegre - RS, Brasil).

LENE, H. Jornais centenários do Brasil. Covilhã: LabCom/UBI, 2020.

O jornal impresso vai acabar? Este foi o questionamento que instigou Hérica Lene (2020) em seu novo trabalho. Jornais centenários do Brasil é um estudo de caráter predominantemente histórico, dedicado aos periódicos nacionais e regionais que possuem 100 ou mais anos de existência. Iniciada em 2014, a pesquisa foi desenvolvida pela autora ao longo de seu pós-doutoramento na Universidade Federal do Rio de Janeiro, concluído em 2018. Os resultados obtidos durante os quatro anos de investigação foram editados pelo laboratório de conteúdos on-line da Universidade da Beira Interior, que disponibilizou o material gratuitamente para leitura em formato eletrônico.

Esta é a segunda obra assinada pela professora da Universidade Federal do Recôncavo da Bahia. O seu primeiro livro, Jornalismo de economia no Brasil (LENE, 2013), originou-se da tese de doutorado sob orientação de Ana Paula

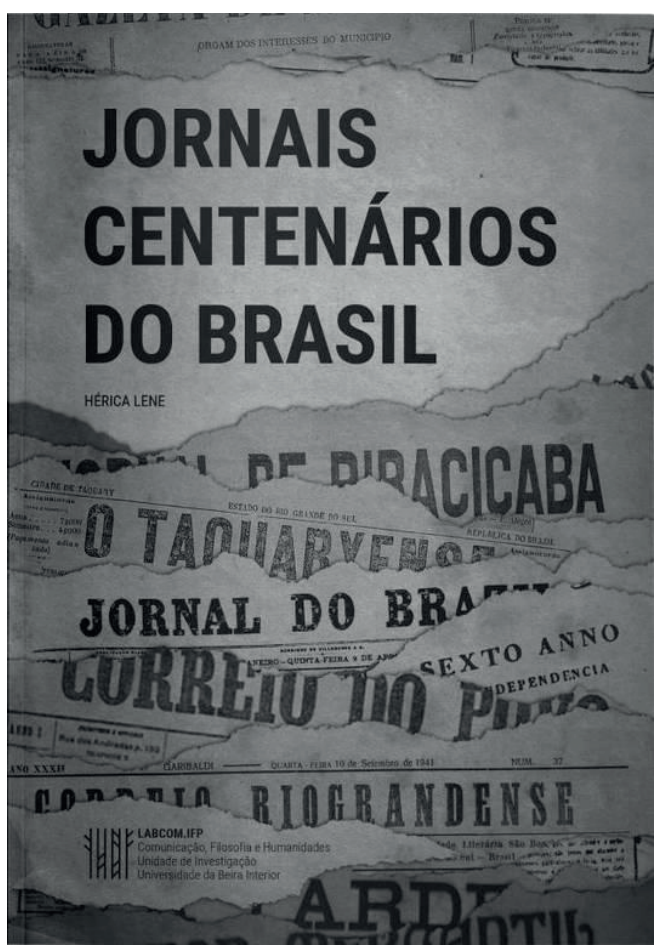
Goulart Ribeiro, na Universidade Federal do

Rio de Janeiro. Trata-se de análise sobre a cobertura jornalística a partir dos programas econômicos implementados no país, após a redemocratização. O interesse pelo tema já havia constado na sua dissertação de mestrado, intitulada A crise da Gazeta Mercantil: tradição e ruptura no jornalismo econômico brasileiro (LENE, 2004), orientada por Marialva Barbosa, na Universidade Federal Fluminense.

Na introdução de seu novo trabalho, Lene (2020) enuncia que sua pesquisa está em sintonia com pressupostos sustentados pelas antigas orientadoras. Apesar de afinidades teóricas existirem, a estudiosa não está, na verdade, trabalhando com as mesmas estratégias 
metodológicas que elas. Por exemplo, inserida no campo de história cultural, Barbosa (2010, p. 15) buscou analisar os diários do Rio de Janeiro a partir do modelo formulado por Robert Darnton, que consiste no estudo do "circuito da comunicação impressa" envolvendo a produção da mensagem até a leitura feita pelo público. Este não é, todavia, o aparato teóricometodológico que configura a investigação dos jornais centenários.

O que não diminui os tantos méritos apresentados por Lene (2020), que empreendeu esforço para realizar vasta pesquisa bibliográfica sobre história da imprensa brasileira, acompanhada de pesquisa documental sobre cada periódico centenário, bem como entrevistas com editores, diretores e chefes de redação. Assim, foram levantadas diversas informações dos 28 periódicos com mais de 100 anos, registrados em listagem fornecida pela Associação Nacional dos Jornais.

O livro está organizado em quatro capítulos, além de conter prefácio - escrito por Barbosa -, introdução e considerações finais. O primeiro capítulo trata dos jornais centenários das regiões metropolitanas, a saber: Diário de Pernambuco (PE), O Estado de S. Paulo (SP), O Fluminense (RJ), Correio do Povo (RS), A Tarde (BA), Jornal do Commercio (AM) e Jornal do Commercio (PE). Depois, ganham vez os interioranos. A região Sudeste concentra o maior número de títulos. Na região Sul, os três periódicos levantados possuem raízes em cidades do Rio Grande do Sul. Já na região Nordeste, apenas A União permanece em atividade, sendo editado em João Pessoa. As regiões Centro-Oeste e Norte não têm representantes.

O terceiro capítulo é dedicado aos sobreviventes que migraram para a plataforma online. O destaque fica por conta do Jornal do Brasil (RJ), um dos noticiários mais importantes do país, que foi restringido ao formato digital em 2010, mas voltou a ser impresso entre os meses de 2018 e 2019. Os demais periódicos listados são: O Mossoroense (RN), Correio Riograndense (RS), A Cidade (SP) e Gazeta do Povo (PR). O capítulo seguinte dirige atenção aos títulos extintos na segunda década do século XXI, a exemplo do Jornal do Commercio (RJ) que circulou de 1827 a 2016.

Dada a quantidade de jornais com que trabalhou, Lene (2020) apresentou mais uma visão panorâmica de cada um deles do que reconstruiu, em detalhe, suas trajetórias. Por um lado, há que se reconhecer o trabalho de síntese realizado a partir de ampla revisão bibliográfica. Mas é verdade que algumas referências centrais não apareceram, como foi o caso dos trabalhos sobre imprensa paulista de Maria Helena Capelato (CAPELATO; PRADO, 1980, CAPELATO, 1989). Por outro lado, cabe observar quais são as implicações contidas nessa abordagem de síntese, uma vez que o resgaste histórico fica limitado, quase sempre, às interpretações já realizadas por outros historiadores. A tendência é de que os jornais que foram objeto de investigações anteriores recebam significantemente mais espaço do que aqueles que ainda não foram devidamente documentados. Pode-se citar o caso do Diário de Pernambuco, que teve sua trajetória periodizada em cinco fases (Império, Primeira República, período 1930-1945, período 1950-1970 e atualidade), ocupando oito páginas do livro. Na mesma seção, a trajetória do Jornal do Commercio de Manaus foi resumida, com menos rigor, em três páginas de texto. 
Outras estratégias adotadas pela estudiosa só enriqueceram o material, a exemplo do levantamento de imagens de capas de edições antigas e recentes de cada jornal, e da realização de entrevistas individuais semiabertas com seus dirigentes. Estas foram capazes de revelar novos modelos de negócio para a sobrevivência da produção de notícias, no cenário de contínua crise. Ao mesmo tempo, é interessante notar como a tradição é apontada frequentemente, pelos entrevistados, como um atributo fundamental para manutenção das empresas jornalísticas no mercado.

O livro termina apresentando um balanço geral, em forma de considerações finais, a partir do que foi exposto nos capítulos anteriores. De modo didático, reúne em 12 itens os principais resultados da pesquisa. Para finalizar, a autora propõe, ainda, um tópico intitulado "entre o tempo histórico e o midiático". Todavia, este fica desconexo na medida em que passa a desenvolver conteúdo de teoria da mídia, em vez de manter o foco no exame do material empírico sobre os 28 centenários. Significa que o tópico anterior — "a crise do jornalismo" - teria fornecido um encerramento mais adequado à obra, que é uma das principais contribuições para o assunto nos últimos anos.

\section{Referências}

BARBOSA, M. História cultural da imprensa: Brasil, 1800-1900. Rio de Janeiro: MauadX, 2010.

CAPELATO, M. H.; PRADO, M. L. O bravo matutino: imprensa e ideologia no jornal "O Estado de S. Paulo”. São Paulo, Alfa-Ômega, 1980.

CAPELATO, M. H. Os arautos do liberalismo: imprensa paulista, 1920-1945. São Paulo: Brasiliense, 1989.

LENE, H. Jornais centenários do Brasil. Covilhã: LabCom/UBI, 2020.

LENE, H. Jornalismo de economia no Brasil. Cruz das Almas: Editora UFRB, 2013.

LENE, H. A crise da Gazeta Mercantil: tradição e ruptura no jornalismo econômico brasileiro. 2004. 255 f. Dissertação (Mestrado em Comunicação) — Universidade Federal Fluminense, Niterói, 2004.

\section{Otávio Daros}

Doutorando em Comunicação Social pela Pontifícia Universidade Católica do Rio Grande do Sul. Fellow do Laboratório de História da Comunicação na Universidade de Bremen. E-mail: otavio. daros@gmail.com.

Recebido em: 06.09.2020

Aprovado em: 26.12.2020

Este artigo é publicado em acesso aberto (Open Access) sob a licença Creative Commons Attribution Non-Commercial (CC-BY-NC), que permite uso, distribuição e reprodução em qualquer meio, sem restrições, desde que sem fins comerciais e que o trabalho original seja corretamente citado.

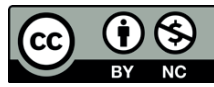

